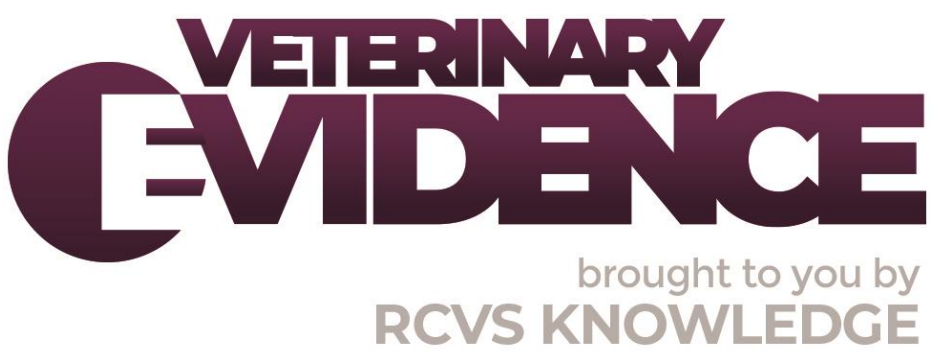

\title{
Thank You to Our Reviewers
}

Peter Cockcroft MA VetMB MSc DCHP DVM\&S DipECBHM MBA MRCVS ${ }^{1 *}$

\footnotetext{
${ }^{1}$ University of Surrey, School of Veterinary Medicine, Daphne Jackson Rd, Guildford GU2 7AL

* Corresponding Author (p.cockcroft@surrey.ac.uk)
}

ISSN: 2396-9776

Published: 016 Jan 2020

in: Vol 5, Issue 1

DOI: 10.18849/VE.V5I1.315 
As Editor-in-chief I would like to thank all of our editors and reviewers for their continued support of the Veterinary Evidence journal and their diligence in meeting demanding timelines. Their knowledge, expertise and insights are duly acknowledged and highly valued. All reviewers who have taken the time to review for Veterinary Evidence are listed below.

The Veterinary Evidence Editorial Board Meeting was held on November 8th. There were some important strategic initiatives discussed and some key action points defined. These included the implementation and promotion of the new format of the clinical bottom line, the implementation of a systematic approach for generating knowledge summary questions for important conditions, initiatives to increase the engagement and scope of topics submitted by veterinary nurses, commissioning of articles on work-placed based education and other key topics, the publication of consolidated annual lists of knowledge summaries identifying weak or no evidence to sign post areas requiring future research and the promotion of quality improvement and audit case studies. I look forward to realising these important initiatives in the coming year and acknowledge the support and dedication of everyone involved in the continued innovation and success of the Journal.

\author{
Nicola Ackerman \\ Victoria Arbona \\ Debbie Archer \\ Sarah Baillie \\ Michael Barnes \\ Jackie Belle \\ Duncan Berkshire \\ Kelly Bowlt Blacklock \\ Katherine Briscoe \\ Matt Brunke \\ Louise Buckley \\ Valentina Busin \\ Sherman Canapp \\ Sarah Caney \\ Thomas Cardy \\ James Carmalt \\ John Carr \\ William Chandler \\ Wye Chong \\ Peter Clegg \\ Peter Cockcroft \\ Jacqueline Cole \\ Polly Compston \\ Elena Contrera \\ Matthieu Cousty \\ Gwendoline Covey-Crump \\ James Patrick Crilly \\ Janny De Grauw \\ Luisa De Risio \\ Nausikaa Devriendt \\ Laura Dixon \\ Pete Down \\ Jacklyn Ellis \\ Debbie Emmerson
}




\author{
Virginia Fajt \\ Erik Fausak \\ John Fishwick \\ Myra Forster-van Hijfte \\ Sam Franklin \\ Barbara Glanemann \\ Nicolas Granger \\ Dai Grove-White \\ Matt Gurney \\ Kelly Hall \\ Anna Hammond \\ Alastair Hayton \\ Melanie Hezzell \\ Andy Hopker \\ Jo Ireland \\ Stephen Jones \\ Nicolette Joosting \\ Alastair Kay \\ Nina Kieves \\ Sean Langton \\ Zofia Lisowski \\ Fiona Margaret Lovatt \\ Emma Love \\ Lynn Martin \\ Vengai Mavangira \\ Elizabeth Mclnnes \\ Tristan Merlin \\ Andy Morris \\ Ronan Mullins \\ Malcolm Ness \\ Peter-John Noble \\ Margaret Nolan \\ Conor O'Halloran \\ Kazuya Oikawa \\ Nick Parkinson \\ Valentin Parmen \\ Catrina Pennington \\ Roberta Perego \\ Robert Pettitt \\ Simon Platt \\ Christopher Bruce Riley \\ Geoff Robins \\ Paul Roger \\ Suzanne Rogers \\ Hilde de Rooster \\ Yves Samoy \\ Michael Schoonover \\ Goncalo Serrano \\ Virginia Sherwin \\ Ellen Singer \\ Josh Slater
}


Bruce Austen Smith

Bryden Stanley

Frank Steffen

Matthew Stewart

Jo Suthers

Adam Swallow

Elisabeth Swann

Sohier Syame

Sienna Taylor

David G Thomas

Mary Thompson

Linda Toresson

Theodora Tsouloufi

Claire Weeks

Constance Neville White

Mikolaj Wojciechowski 


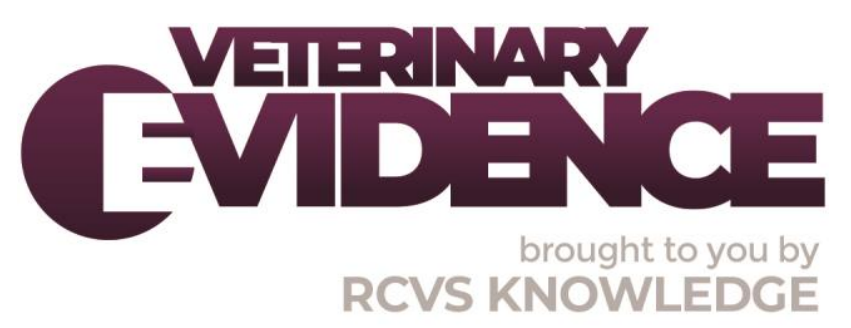

\section{Intellectual Property Rights}

Authors of Knowledge Summaries submitted to RCVS Knowledge for publication will retain copyright in their work, and will be required to grant RCVS Knowledge a non-exclusive license of the rights of copyright in the materials including but not limited to the right to publish, re-

publish, transmit, sell, distribute and otherwise use the materials in all languages and all media throughout the world, and to license or permit others to do so.

\section{Disclaimer}

Any opinions expressed in articles and other publication types published in Veterinary Evidence are the author's own and do not necessarily reflect the view of the RCVS Knowledge. Veterinary Evidence is a resource to help inform, and the content herein should not override the responsibility of the practitioner. Practitioners should also consider factors such as individual clinical expertise and judgement along with patient's circumstances and owners' values. Authors are responsible for the accuracy of the content. While the Editor and Publisher believe that all content herein are in accord with current recommendations and practice at the time of publication, they accept no legal responsibility for any errors or omissions, and make no warranty, express or implied, with respect to material contained within.

For further information please refer to our Terms of Use.

RCVS Knowledge is the independent charity associated with the Royal College of Veterinary Surgeons (RCVS). Our ambition is to become a global intermediary for evidence based veterinary knowledge by providing access to information that is of immediate value to practicing veterinary professionals and directly contributes to evidence based clinical decision-making.

https://www.veterinaryevidence.org/

RCVS Knowledge is a registered Charity No. 230886.

Registered as a Company limited by guarantee in England and Wales No. 598443.

Registered Office: Belgravia House, 62-64 Horseferry Road, London SW1P 2AF

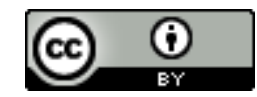

This work is licensed under a Creative Commons Attribution 4.0 International License. 